\title{
A Study of Coast Protection Constructions Built with the use of Recycled Construction Materials and their Negative Impact
}

\author{
Balzannikov M.I., Mikhasek A.A., Galitskova Yu.M. \\ Samara State Technical University, Institute of Architecture and Civil Engineering \\ Address: Molodogvardeyskaya St., 194, Samara, 443001, Russia
}

\begin{abstract}
Different types of materials are used in hydraulic structures and coast protection constructions. These materials can be of natural (e.g. stone) and artificial origin (concrete, metal). The main trends typical for building construction now are as follows: cutting a share of natural materials and reusing waste products of dismantling construction objects.

As a result of recycling it is possible to produce building materials that look like and have properties characteristic of natural stone materials, gravel, in particular. While gravel is being processed, it is possible to predict that it would obtain such characteristics as grade, frost resistance and strength. Reuse of recycled construction materials is a challenge, because this type of waste can hardly be reduced in volume and requires considerable space for burial.

We propose to use gravel produced by processing in hydraulic engineering objects, i.e. in coast protection constructions. For that, we analyzed waste materials characteristics to justify their use in hydraulic structures. The research proved that strength of gravel produced by processing was sufficient enough. On the other hand, its frost resistance and fineness did not satisfy the requirements to materials used in coast protective structures. Besides, the construction of such structures causes water pollution as inert materials placed in waterbodies increase water turbidity. As a large part of the structure is located directly in the waterbody, during the period of the construction inert materials are supposed to be dumped. In this period the water body is filled with a significant amount of fine particles, which leads to an increase in turbidity at the construction site.

Thus, we come to the conclusion that it is possible to reuse recycled construction materials in hydraulic engineering structures only on condition of their additional after-treatment processing. We offer to mix gravel produced by processing with cement mortal. As a result we obtain no-fines concrete, which is further processed by hot procedure (with bituminous materials).

No-fines concrete can be produced in the form of precast units of $1,4 \times 1,4 \times 0,5 \mathrm{~m}$. The use of prefabricated units will allow to avoid waterbody pollution and protect it from fine particles. Further processing by bituminous materials will enhance its frost resistance and reliability, which in turn will prevent contamination of the water body in the period of coast protection constructions usage.
\end{abstract}

Keywords: coast protection, waterbody, industrial wastes, pollution, gravel, asphalt concrete.

\section{INTRODUCTION}

Different kinds of materials can be used when erecting waterworks, including coast protection structures [1, 2]:

- of natural origin: stone,

of artificial origin: concrete, metal, etc.

The most promising trends of construction are aimed at reducing the share of newly developed natural materials and increasing reuse of such products from recycled materials as wastes of construction objects dismantling.

Our studies [3, 4], devoted to the possibility of reusing products of construction structures dismantling, put forward technologies of these structures crushing. As a result of recycling it is possible to produce building materials that look like and have properties characteristic of natural stone materials, gravel, in particular.
The use of wastes in the form of gravel in hydraulic structures is associated with water pollution. The reason for that lies in the fact that inert materials with fine parts enhancing turbidity are used in the construction of such waterbodies.

Thus, it is actual to undertake a research in this field and find ways to reduce the negative impact of the construction of coast protection structures using products of recycling building materials.

\section{MATERIALS AND METHODS}

Reuse of recycled construction materials is a challenge, because this type of waste can hardly be reduced in volume and requires considerable space for burial.

We propose to use gravel produced by processing in hydraulic engineering objects, i.e. in coast protection constructions. For that, we analyzed waste http://dx.doi.org/ 10.17770/etr2017vol1.2639 
materials characteristics to justify their use in hydraulic structures. Table 1 presents data on the composition of the produced gravel.

Table I

The composition of the produced gravel.

\begin{tabular}{|l|c|}
\hline \multicolumn{1}{|c|}{ Type of material } & \multicolumn{1}{|c|}{$\begin{array}{c}\text { Content \% } \\
\text { (no more) }\end{array}$} \\
\hline $\begin{array}{l}\text { Concrete and reinforced } \\
\text { concrete }\end{array}$ & $0-95$ \\
\hline Brick & $0-95$ \\
\hline Slate & 5 \\
\hline Metal & 2 \\
\hline Polymers & 1 \\
\hline Wood & 1 \\
\hline Glass & 1 \\
\hline
\end{tabular}

After reviewing the requirements for materials used in hydraulic structures, the authors tried to reduce negative impact of building coast protection structures while using products of recycling construction materials and put forward the following requirements:

- size of material should not be less than 100-400 $\mathrm{mm}$;

- its strength should not be less than $400 \mathrm{~kg} / \mathrm{m}^{3}$;

- its frost resistance should be of at least 100 cycles.

Preliminary screen separation of crushed products makes it possible to reduce the volume of fine dispersed phase, which in its turn, reduces the water body pollution.

Low frost resistant properties of the obtained gravel lead to the conclusion that as a result of materials destruction there occur materials washing out into a water object and its repeated contamination during the period of operation. In this connection, the study of frost resistant properties of crushed wastes of building structures seems quite actual.

When performing research, we used:

- freezing chamber, providing and maintaining the temperature up to minus $(18 \pm 2)^{\circ} \mathrm{C}$;

- drying chamber;

- analytical balances;

- sieves;

- a bath for saturating the water and for thawing;

- a metallic vessel.

An analytical sample of crushed wastes was put into a metal container and covered with water at a temperature of $+20^{\circ} \mathrm{C}$.

After the period of 48 hours, the product was moved into the freezing chamber at a temperature of $18^{\circ} \mathrm{C}$. The freezing cycle rate was four hours.

After that, the samples were heated to a temperature of $+20^{\circ} \mathrm{C}$ and were matured for at least two hours. Further the test cycles were repeated.

After every five cycles, the samples were dried to their constant weight, screened out through a control sieve and were left there before further testing. Grains the the samples which had a fresh surface of fracture were considered being of low frost-resistance.
The loss of samples weight $\Delta \mathrm{m} \Delta \mathrm{m} \Delta \mathrm{m}, \%$, was determined from the formula (1):

$$
\Delta m=\frac{m-m_{1}}{m} \times 100 \%
$$

where $\mathrm{m}$ is the mass of the sample before testing, $\mathrm{g}$; $\mathrm{m}_{1}$ if the weight of sieve residue after a cycle of freezing and thawing, $\mathrm{g}$.

\section{RESULTS AND DISCUSSION}

The research results of frost resistance of recycled construction materials are shown in Table 2.

Table II

The research results of frost resistance of construction materials crushed wastes

\begin{tabular}{|c|c|c|}
\hline $\begin{array}{c}\text { The number of test } \\
\text { cycles }\end{array}$ & Weight, g. & Weight loss, \% \\
\hline 0 & 1684 & 0 \\
\hline 15 & 1674 & 0.59 \\
\hline 30 & 1672 & 0.71 \\
\hline $\mathbf{4 5}$ & $\mathbf{1 5 7 0}$ & $\mathbf{6 . 7 6}$ \\
\hline $\mathbf{7 5}$ & $\mathbf{1 5 3 0}$ & $\mathbf{9 . 1 4}$ \\
\hline
\end{tabular}

The data analysis of Table 2 show that the value of frost resistance is only 30 cycles, with the required amount of 100 cycles. Thus, it can be concluded that a structure built of recycling construction materials will cause pollution.

Therefore, it is required to improve properties of recycling construction materials. To do this, recycling construction materials should acquire desired characteristics of size, fineness, frost resistance, durability and strength.

We suggest processing these materials with cement mortar. As a result, we' 11 get a material with different characteristics (see Figure 1). Its frost resistance properties are given in Table 3.

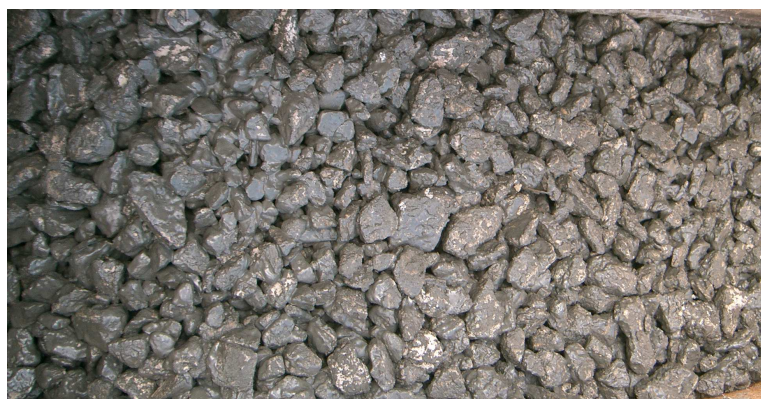

Fig. 1. Type of coarse-pored concrete

Table III

Research results of frost resistance of no-fines concrete obtained from building structures wastes

\begin{tabular}{|c|c|c|}
\hline $\begin{array}{c}\text { The number of test } \\
\text { cycles }\end{array}$ & Weight, g. & Weight loss, \% \\
\hline 0 & 1698 & 0 \\
\hline 15 & 1684 & 2.0 \\
\hline 30 & 1674 & 3.44 \\
\hline 45 & 1664 & 4.87 \\
\hline $\mathbf{7 5}$ & $\mathbf{1 6 5 2}$ & $\mathbf{6 . 5 9}$ \\
\hline
\end{tabular}


The data analysis of Table 3 show that the value of frost resistance increased up to 50 cycles.

We also studied strength characteristics of nofines concrete [5]. During the tests, samples of nofines concrete were crushed at a press. Average strength of $20-40 \mathrm{~mm}$ gravel with cement consumption of $150 \mathrm{~kg} / \mathrm{m}^{3}$ equaled $45 \mathrm{~kg} / \mathrm{cm}^{2}$.

Due to the connection between factions of nofines concrete, it possible to use products of less than $100 \mathrm{~mm}$ size in ice and wave conditions.

Besides, no-fines concrete can be made in the form of precast units of $1,4 \times 1,4 \times 0,5 \mathrm{~m}$ (with account of its sustainability to ice loads) [6] in a concrete plant, delivered to a place of stacking and assembled on a coast protection site.

The proposed technology eliminates washout or demolition of fine particles into the water body and its consequent pollution.

However, according to Table 3 , it is not enough to use only no-fines concrete In this regard, we also propose to process slabs of no-fines concrete by a hot procedure with bituminous materials.

\section{CONCLUSION}

1. Reuse of recycled construction materials is a challenge, because this type of waste can hardly be reduced in volume and requires considerable space for burial.

2. As a result of crushing it is possible to produce building materials that look like and have properties characteristic of natural stone materials, gravel, in particular.

3. It is not possible to use recycled construction materials in hydraulic engineering structures without additional processing as it will lead to a waterbody pollution with fine particles contained on the surface of large grains.

4. To reduce a negative impact of using recycled construction materials in hydraulic engineering structures, it is required to improve these materials.

5. In the course of further wastes processing after crushing, it is possible to form in them such improved features as grade, frost resistance and strength.

6. To improve the properties of waste products, we offer to mix them with cement mortal. As a result we obtain no-fines concrete, which is further processed by hot procedure (with bituminous materials).

7. No-fines concrete can be produced in the form of precast units of $1,4 \times 1,4 \times 0,5 \mathrm{~m}$. The use of prefabricated units will allow to avoid waterbody pollution and protect it from fine particles. Further processing by bituminous materials will enhance its frost resistance and reliability, which in turn will prevent contamination of the water body in the period of coast protection constructions usage.

\section{REFERENCES}

[1.] Balzannikov M.I., Mikhasek A.A. The use of modified composite materials in building hydraulic engineering structures. Procedia Engineering, V.91, 2014, pp.183-187.

[2.] Mikhasek A.A., Smyvalov A.A. Basis of selection design of coast protection structures from composite materials. Scientific Survey, 14, 2015, pp.102-109.

[3.] Mikhasek A.A., Galitskova Yu.M. Using wastes in industrial and hydraulic facilities construction. Industrial and civil engineering, 6, 2015, pp.31-34.

[4.] Mikhasek A.A., Galiyskova Yu.M., Tutova O.A. The use of crusher-run aggregates of reinforced concrete frames when reconstructing hydraulic structures. Procedia Engineering. V.153, 2016, pp.456-460.

[5.] Shabanov V.A., Mikhasek A.A. Technology of waterrepellent barrier design in "hard emcoastments». Installation and special works, 11, 2006, pp. 11-13.

[6.] Balzannikov M.I., Kholopov I.S., Rodionov M.V., Litvinova M.G. Theoretical studies of the work of coast-protecting concrete-filled textile mats in conditions of ice impacts. Scientific Survey, 22, 2015, pp. 65-71.

[7.] Balzannikov M.I., Popov V.P., Mikhasek A.A. Study results assessment of quick-hardening liquids penetration into soil elements of hydraulic engineering constructions. Procedia Engineering, V. 153, 2016, pp. 71-76. 